Article

\title{
Application of Life Cycle Sustainability Assessment to Used Lubricant Oil Management in South Brazilian Region
}

\author{
Malaquias Zildo António Tsambe ${ }^{1, *}$, Cássio Florisbal de Almeida ${ }^{2}$, Cássia Maria Lie Ugaya ${ }^{3}$ \\ and Luiz Fernando de Abreu Cybis ${ }^{2}$ \\ 1 Department of Studies in Environmental Technologies, Faculty of Natural Science and Mathematics, \\ Pedagogical University of Maputo, Av. do Trabalho, Maputo 2482, Mozambique \\ 2 Post-Graduation Program in Hydric Resources and Environmental Sanitary, Federal University of Technology \\ of Rio Grande do Sul, Av. Bento Gonçalves, Porto Alegre 9500, Brazil; cassiofalmeida@gmail.com (C.F.d.A.); \\ luiz.cybis@ufrgs.br (L.F.d.A.C.) \\ 3 Post-Graduation Program in Mechanical Engineering and Materials, Federal University of \\ Technology_Paraná, Av. Sete de Setembro, Curitiba 6681, Brazil; cassiaugaya@utfpr.edu.br \\ * Correspondence: m.tsambe@gmail.com; Tel.: +258-8281-47570
}

check for updates

Citation: Tsambe, M.Z.A.; de Almeida, C.F.; Ugaya, C.M.L.; de Abreu Cybis, L.F. Application of Life Cycle Sustainability Assessment to Used Lubricant Oil Management in South Brazilian Region. Sustainability 2021, 13, 13583. https://doi.org/ $10.3390 /$ su132413583

Academic Editors: Athanasios Angelis Dimakis and Marc A. Rosen

Received: 25 August 2021

Accepted: 28 November 2021

Published: 8 December 2021

Publisher's Note: MDPI stays neutral with regard to jurisdictional claims in published maps and institutional affiliations.

Copyright: (c) 2021 by the authors. Licensee MDPI, Basel, Switzerland. This article is an open access article distributed under the terms and conditions of the Creative Commons Attribution (CC BY) license (https:/ / creativecommons.org/licenses/by/ $4.0 /)$.

\begin{abstract}
Used Lubricant Oil (ULO) is a hazardous waste resulting from lubricant oil used in motorized equipment to reduce friction between moving surfaces that, over time, wear outs and becomes contaminated. The purpose of this study is to compare the sustainability of two ULO management systems in Brazil: one designated in this study by the TTR scenario (which includes transportation, trans-shipment, and re-refining phases), the other designated by the TsTR scenario (without the trans-shipment phase) to evaluate which scenario is socially, economically, and environmentally more efficient. The study uses the life cycle sustainability assessment (LCSA) methodology. As a combination of life cycle assessment (LCA), life cycle cost (LCC), and social life cycle assessment (s-LCA), it integrates the three sustainability dimensions (environmental, social, and economic). The sustainability index was calculated by aggregating data from eight environmental indicators, five economic indicators, and five social indicators. The results showed that the TsTR scenario presented the best values for the sustainability assessment than the TTR scenario. The TsTR scenario had the best social and economic performance, and the TTR scenario had the best environmental performance. The differences observed in those scenarios' performances were noted by the absence or presence of the trans-shipment center. The absence of this center improved the social and economic performance of the scenario. The social dimension was improved by the elimination of the stage that causes problems related to social and economic dimensions by reducing several costs that can be associated with it. The presence of the trans-shipment center improves the environmental performance scenario by reducing the number of hazards that could impact the re-refining phase. The LCSA methodology enables a comparative life cycle assessment of two alternative system evaluations of ULO management by the sustainability index of each scenario. This index helps to analyze the contributions of each of the 18 categories and subcategories in the perspective of the sustainability dimensions and, consequently, to carry out their integrated evaluation, aiming to define the best sustainability scenario.
\end{abstract}

Keywords: Used Lubricant Oil (ULO); life cycle assessment (LCA); social life cycle assessment (s-LCA); life cycle cost (LCC); life cycle sustainability assessment (LCSA)

\section{Introduction}

ULO is a product formed when lubricating oil is used in motorized equipment to reduce friction that, over time, wears out and becomes contaminated with metals from rubbed surfaces, organic materials, and other products, thus reducing its quality [1,2]. When the amount of these contaminants is excessive, the lubricant loses its quality and needs be replaced. At this stage, the lubricants become ULOs [3]. In Brazil, as in many other 
countries, ULO lacks a specific management system (collection and subsequent treatment) since in several urban centers, when generated, it is released directly into the environment (in water, sewage networks, and soil) and sometimes burns uncontrollably [4]. Globally, in 2015, lubricating oil consumption averaged 35 million tons a year [1]. Brazil became the world's sixth largest consumer of lubricating oils, responsible for approximately 1.5 billion liters of lubricating oil consumption each year and becoming the sixth largest ULO producer $[2,4]$.

According to the re-refineries' union, the ULO collection service covers most of the Brazilian municipalities, and there are currently around 50 collection centers distributed throughout different regions. The southern region of Brazil gathers $20 \%$ of these collection centers as a result of the presence of the second largest ULO generation source and, consequently, the second largest management park for this waste. From 2012 to 2016, there was an increase in national coverage in relation to collection, with collections rising from $37 \%$ (367 million liters) to $40 \%$ (404 million liters) in 2016. In terms of region, the south Brazilian region has collected $38 \%$ (corresponding to approximately 154 billion liters of ULO) $[5,6]$.

Depending on the composition of the ULO (80-85\% are composed of basic oil), this waste can have various destinations, such as disposal (by incineration), recycling, and reprocessing [7]. Thus, each country or region defines a legal destination for this waste based on the different forms of treatment that it can be given. Currently, the European Union (EU) defines the different levels of treatment for ULO based on its economic and calorific value. The re-refining and direct burning correspond to $70 \%$ of the mass of the collected ULO, and the other two processes used, reprocessing and recovery (used for hydraulic oils), are responsible for the remaining $30 \%$ of the mass of the oil collected $[7,8]$. Brazil defines the re-refining process as the main method for final disposal and minimization of ULO waste [9].

Traditionally, life cycle performance assessment systems for a product or service have been based on methodologies that cover the assessment of environmental impacts (through LCA). LCA has limitations when used for decision making because it only considers the environmental dimension in the analysis of alternatives related to a productive process [10]. Due to this, it is necessary to evaluate a production system from the perspective of sustainability, which encompasses social, economic, and environmental dimensions. This would be a more comprehensive perspective, considering that it combines the three different dimensions of sustainability into the "triple bottom line" principle, the life cycle sustainability assessment of a product [11-13]. Research on the application of the LCSA methodology is relatively recent [13] and refers to 2010 as the year of LCSA development, aiming to find answers to questions related to sustainability. The methodology encompasses the three dimensions of sustainability, of which the social dimension is relatively new, and there are not many studies on this [14]. Thus, the emergence of the first studies using the LCSA methodology is the consequence of the development of studies relating to s-LCA [11,15]. Studies and other instruments $[14,16-18]$ constitute the tools used to evaluate this ULO LCSA. One particularity of the present case study is the use of the sustainability index as a tool that defines the degree of sustainability. It combines different indicators of each sustainability dimension and evaluates the environmental, economic, and social issues associated with the ULO management system in southern Brazil to define the optimal scenario.

There are plenty of studies regarding the LCA or LCC of different used oils [14,19-22], however, besides having environmental problems to be analyzed, the ULO system has several social problems often caused by the economic sense of the cycle. In this sense, the research provides an assessment of the ULO life cycle that goes beyond the environmental dimension. The paper aims to assess the sustainability of ULO management in the southern Brazilian region through an analysis of two management systems currently in use. It aims to compare the social, environmental, and economic parameters of the TTR and TsTR systems according to the many individual indicators with an adequate multicriteria evaluation. 
This study will provide an overview of the better scenarios of sustainability for the ULO management system that will help decision makers to redefine necessary transformations.

\section{Materials and Methods}

This research was based on the LCSA methodology of management and technology processes applied to ULO re-refining. This methodology is based on the three sustainability pillars with the aim of relating the various indicators to the functional unit and restricting them to a manageable and comparable unit [14] and to highlight the characteristics of LCSA when combining, without formal weighting, LCA, LCC, and s-LCA. The conjugation phase of the three sustainability dimensions was implemented in the interpretation of the results with the respective sustainability factors and indices. Thus, it did not abdicate the LCA's interactive nature. In this perspective, authors such as $[11,13,14,23,24]$ highlight the necessity of sustainability dimension conjugation complemented by a multivariate analysis of the impacts verified in each assessed dimension.

\subsection{Functional Unit}

The functional unit of this study was the treatment of $1 \mathrm{~kg}$ of basic oil obtained from ULO re-refining.

\subsection{Objective and Scope}

The study was limited to three stages (generation, collection/trans-shipment, and re-refining) through a cradle-to-gate perspective. In addition, two LCSA scenarios were defined based on existing ULO management systems. The first scenario, designated by the TTR system (Transportation with Trans-shipment and Re-refining) - which included the generation stage processes (which considers the ULO entry phase to the cycle), ULO transportation to the collection/trans-shipment center (which considers the ULO collection phase from the generation site to the trans-shipment), and subsequent transport to the re-refinery (where the basic oil production occurs). The second scenario, designated by the TsTR system (Transportation without Trans-shipment and later Re-refining), is characterized by the exclusion of collection/trans-shipment centers. In this system, the ULO is transported directly from the generation site to the re-refinery. In the TTR system, the collection center (trans-shipment) functions as the site of ULO qualification through the various physical-chemical analyses with a categorizing purpose. In this pre-treatment, the ULO is concentrated by eliminating part of the water by decanting and defining the quality for re-refining purposes, avoiding the need to do so in the re-refining stage, as occurs in the TsTR scenario (Figure 1).

The definition of these two scenarios is related to the need for evaluating the ULO environmental management system and its economic efficiency combined with the promotion of social benefits. The product system definition and boundaries have been enhanced in light of the information gathered from the corporate institutional documents, technical visits to the re-refining company, collection/trans-shipment centers, and ULO generation sites. Beside the ULO itself, a co-product is generated by this process. Due to these reasons, in the environmental dimension, allocation procedures were necessary in the re-refining stage because, in addition to the basic oil, it generated asphalt, varying quantitatively in both scenarios. In the economic dimension, the need for allocating the various costs not contemplated (goods and services), related to the ULO generation phase, was considered. In the economic dimension, allocation is inevitable due to the diverse goods and services associated with a given production system [25]. Inflation was assumed to be zero $(0 \%)$. This possibility can be assumed when the presented data set refers to the average costs of the goods and services that constitute the process without significant changes in the period under analysis [19]. 


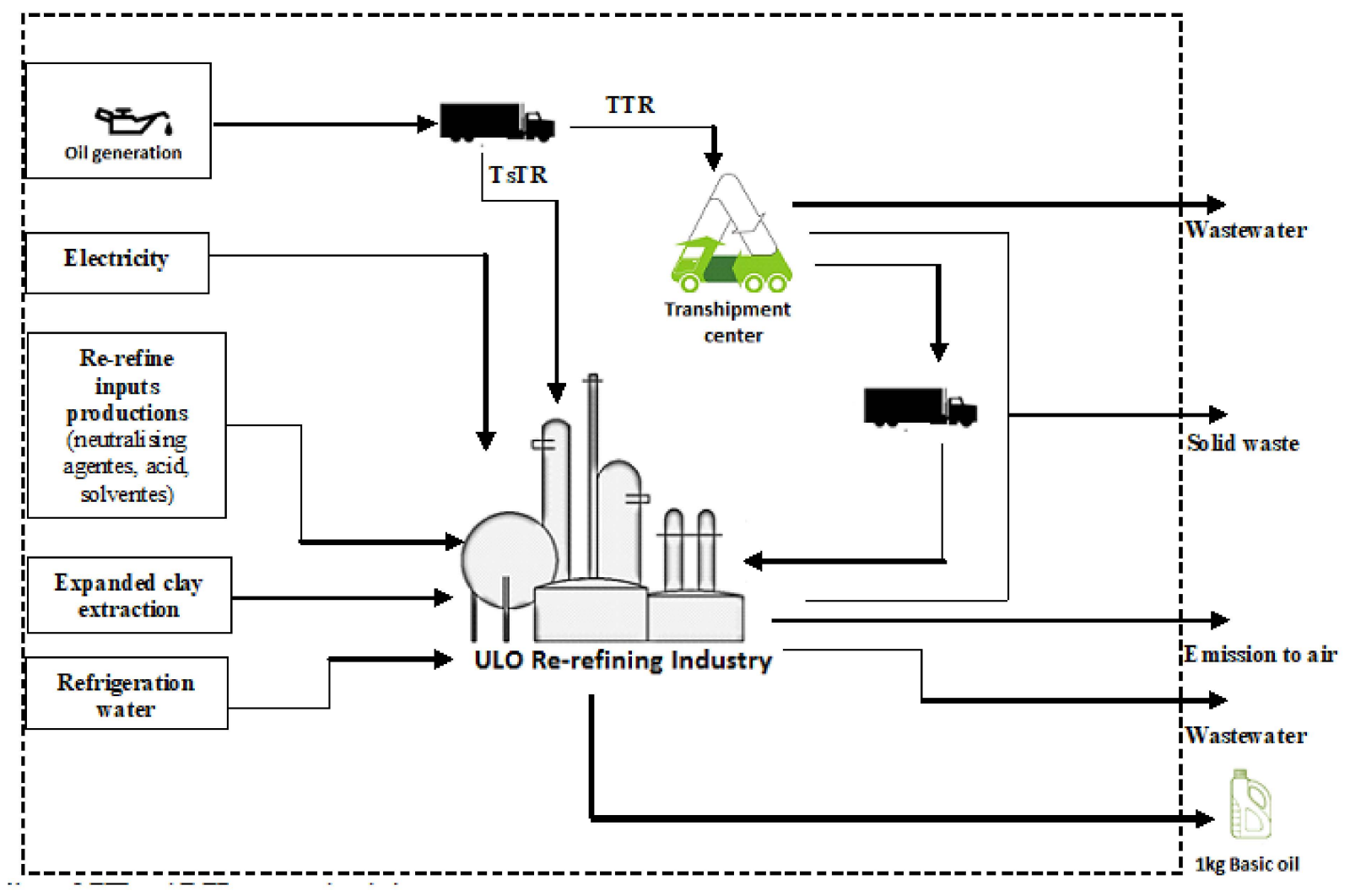

Figure 1. Description of TTR and TsTR systems.

\subsection{Inventory}

The environmental, economic, and social primary data were obtained from technical visits, interviews, and laboratory analysis reports, while secondary data were obtained through the information from FEPAM (State Foundation for Environmental Protection) and SINDIRREFINO (National Syndicate of the Mineral Oil Re-refining Industry) relating to the operating licenses and institutional reports from 2014-2018. The data were transcribed and modeled for a common unit while considering elements related to the defined inventory dimensions. An analysis was performed based on the qualitative and quantitative characteristics of each dimension of data through a technique analysis of the category and the content [26].

The environmental dimension was evaluated according to the LCA perspective recommended by ISO 14040:2006 and ISO 14044:2006 [27,28]. The data relating for this dimension were typically primary data with the exception of transport data obtained from Eco Invent database 3.1 [26]. The impact of the categories was calculated according to a hybrid method "IMPACT 2002+ for ULO v2.12/IMPACT 2002+" as a result of the combination of Impact $2002+$ (2.12) and the ILCD 2011 Midpoint + (1.06). This was to aggregate the previously defined categories for assessment, some of which were present in the Impact 2002+ and others in the ILCD 2011. Eight impact categories were defined according to their potential contributions to the environmental impact of the similar cycle: Land Occupation (LO), Non-Renewable Energy (NRE), Global Warming Potential (GWP), Aquatic Acidification Potential (AAP), Aquatic Eutrophication Potential (AEP), Human Toxicity Potential (HTP), Terrestrial Ecotoxicity Potential (TEP), and Carcinogens Potential (CP). The calculations were performed in Simapro 8.2.3.0. This methodology was applied in ULO LCA studies such as those found in $[2,20,22,24,29]$.

The economic performance assessment of a product or service is made based on the production costs and the costs related to its life cycle. LCC is the sum of all costs associated with the product life cycle encompassing one or more actors of the product. The actors are responsible for financially covering the cost of past, present, and future cycle produc- 
tions [23]. Since 2006, UNEP/SETAC has been improving and standardizing convergent models for evaluating product sustainability. For this purpose, the LCC methodology has been harmonized by the conjugate of the UNEP's Environmental Life Cycle Cost (A code of practice) guide, ISO 15663:2001 [30,31]. This highlights some of the challenges posed by the LCC such as the volatility of physical costs and the non-applicability of the system's expansion operations and its subdivision into several systems for the allocation of impacts recommended by $[27,28]$. Another aspect is the absence of a phase equivalent to that of the impact assessment phase as in "traditional" LCA because the inventory already offers results in the same monetary reference [30]. This approach was defined while taking into account LCC inventory work undertaken during concept selection, including the identification of stage options of the life cycle together with the corresponding outline engineering and design, all culminating with the system limits. In this study, the LCC was characterized by the use of interest rates (often coupled with the individual costs of the process) rather than inflation and the relationship between the different costs incurred that together provide the life cycle [26,31-33]. This approach aimed to combine the perspective of the need to adopt a common and consistent LCC approach in the petroleum, petrochemical, and gas industries [34]. For the LCC, the impacts were also defined based on the functional unit and, above all, the costs related to the ULO management phases. Thus, the costs were categorized into five impact categories: installation costs, initial acquisition costs, transport costs, net replacement costs, and operation and maintenance costs. The impact categories calculated in each of the stages served as a base to evaluate the economic cycle effects. The LCC was defined from monetary values, in Brazilian Reais (BRL), in each evaluated category component [7]. The methodology defines a systematic consideration of costs and revenues associated with an alternative option by an interactive process of planning, estimating, and monitoring costs and revenue differences throughout the life cycle [32-34].

S-LCA enables the assessment of the potential social impacts linked to the production process throughout the life cycle $[15,16]$. Stakeholders are the main concern for directly measuring the parts that make up the life cycle because they are linked to the company's behavior, socioeconomic processes, or to social capital impacts. They allow the identification of improvements in the product or service social performance at different life cycle stages, providing intrinsic information of products for different actors (companies, consumers, and others), as well as the identification of relevant social indicators, influences on the product, or service marketing [35]. This methodology is in the development phase, therefore it is common to have several approaches, but all of them are convergent [36]. S-LCA's main challenge is related to the assessment impact corresponding phase wherein data from the inventory assessment must be converted to the corresponding social impact calculation. This phase occurs through the use of characterization and weighting systems [16,37]. In this perspective, [38,39] developed the Subcategory Assessment Method (SAM) as a way of reducing the subjectivity of the data obtained in the social inventory. The latter authors considered the need for considering the social context in which stakeholders are embedded and used semi-quantitative indicators that made the evaluation of each subcategory more objective and transparent. SAM is a characterization method that evaluates an organization's social profile based on its social behaviors relating to the need to meet basic requirements (BR) in each subcategory throughout the cycle [38]. For this method, BR is a reference through which it is possible to understand the data obtained in the inventory phase. The method consists of an organizational hierarchy of levels, from A to D. Level B implies that the organization meets the BR (e.g., compliance with the country legislation for a given subcategory). Those organizations assigned as level $\mathrm{A}$ are proactive, characterized by good practice throughout the cycle, while levels $C$ and $D$ are assigned to those organizations that do not meet the basic requirements. The difference between levels $\mathrm{C}$ and $\mathrm{D}$ is observed by considering the stage of the organization in the context of the region and/or sector wherein it is inserted [39]. There are five social indicators selected for workers' stakeholders: working hours, fair salary, freedom of association and collective bargaining, health and safety, and child labor. 


\subsection{Sustainability Assessment}

Initially, each dimension was evaluated separately in order to obtain the results of each dimension. Interpretation was performed by considering the standards and guide assumptions as well as the specific studies of each life cycle. Once the LCIA was obtained, its values were converted into contribution percentages of each indicator in the respective life cycle in order to allow comparison and analysis between them [26,39,40]. According to each influence on the analyzed impact category, sustainability indicators were distinguished into positives and negatives. This categorization was based on their contribution to sustainability [14]: the positive indicators would be those that positively influence (by their high values) the impact of the analyzed sustainability category (social indicators), while negative indicators would be those that negatively influence (by their high values) the impact of the respective sustainability assessed categories (economic and environmental indicators). In this perspective, the authors suggested the scoring of each indicator on a scale from 1 to 5 according to the degree of its contribution to each of the dimensions of sustainability. These scores are used to define the magnitude of each impact category in sustainability. This enables comparing not only the categories defined in each dimension, but also the ULO management scenarios established for the LCSA. The subsequent phases were the results obtained through conjugation and evaluation to obtain the comparison analysis through the indicators and indexes. This made it possible to carry out the ULO LCSA [14,41,42].

The expression represented by Equation (1) is obtained by a combination of the instruments used in the evaluation of sustainability through sustainability factors that interpret sustainability separately. In calculating the sustainability index, the factors that describe the arithmetic means of the contributions of each impact in each dimension are considered. The sustainability index is a numerical value derived from the interpretation of the "triple bottom line" sustainability principle. It results from a conjugation of the expressions suggested by $[14,18,32-44]$.

\begin{tabular}{|c|c|c|c|}
\hline $\begin{array}{l}\text { Sustainability } \\
\text { index } \\
\text { IS }\end{array}$ & $\begin{array}{c}\text { Environmental } \\
\text { Sustainability Factor } \\
=\Sigma\left[(\mathrm{Ia} .100 \%) / \mathrm{I}_{\mathrm{iA}}\right]\end{array}$ & $\begin{array}{c}\text { Economic } \\
\text { Sustainability Factor } \\
\Sigma\left[(\text { Ie. } 100 \%) / \mathrm{I}_{\mathrm{E}}\right]\end{array}$ & $\begin{array}{l}\text { Social } \\
\text { ustainability Factor } \\
\Sigma\left[(\text { Is. } 100 \%) / \mathrm{I}_{\mathrm{is}}\right]\end{array}$ \\
\hline
\end{tabular}

where: IS—sustainability index; I—contribution degree (a-environmental, e-economic, and s-social); Ii-reference degree contribution (environmental, economic, and social).

Based on the expression, the obtained weighted results of the environmental, social, and economic impacts were converted into a sustainability index, an instrument that enables the evaluation of the ULO life cycle sustainability degree of the TTR and TsTR scenarios.

\section{Results and Discussion}

This section presents the results and discussion of each dimension and, consequently, the sustainability assessment.

\subsection{Environmental Assessment}

In each scenario, the environmental dimension was made up of two equivalent but distinct stages. The TTR scenario was constituted by a stage that included generation, transportation, and collection with trans-shipment and a second stage referring to the rerefining process. The TsTR scenario was constituted by a stage that encompassed collection and generation without trans-shipment and the second referred to the re-refining process. Table 1 shows the results of the calculations of the life cycle inventories (mass and energy flows), according to the two predefined scenarios (TTR and TsTR). 
Table 1. Environmental impact category results of the ULO life cycle.

\begin{tabular}{|c|c|c|c|c|c|c|c|}
\hline \multirow[b]{2}{*}{ Categories } & \multirow[b]{2}{*}{ Units } & \multicolumn{2}{|c|}{ TsTR Stage Scenario } & \multicolumn{2}{|c|}{ TTR Stage Scenario } & \multicolumn{2}{|c|}{ Total } \\
\hline & & $\begin{array}{l}\text { Transport without } \\
\text { Trans-Shipment }\end{array}$ & Re-Refining & $\begin{array}{l}\text { Transport with } \\
\text { Trans-Shipment }\end{array}$ & Re-Refining & TsTR & TTR \\
\hline Carcinogens & $\mathrm{kg} \mathrm{C}_{2} \mathrm{H}_{3} \mathrm{Cl}$ eq & $1.11 \times 10^{-3}$ & 2.32 & $1.40 \times 10^{-3}$ & 2.20 & 2.32 & 2.20 \\
\hline Terrestrial ecotoxicity & kg TEG soil & 5.54 & $1.03 \times 10^{3}$ & 6.96 & $9.83 \times 10^{2}$ & $1.03 \mathrm{E}+03$ & $9.80 \times 10^{2}$ \\
\hline Land occupation & $\mathrm{m}^{2}$ org.arable & $4.86 \times 10^{-3}$ & 2.45 & $6.09 \times 10^{-3}$ & 2.32 & 2.46 & 2.33 \\
\hline Acidification & $\mathrm{kg} \mathrm{SO}_{2} \mathrm{eq}$ & $8.35 \times 10^{-4}$ & $1.99 \times 10^{-1}$ & $1.05 \times 10^{-3}$ & $1.21 \times 10^{-1}$ & $2.00 \times 10^{-1}$ & $1.23 \times 10^{-1}$ \\
\hline Eutrophication & $\mathrm{kg} \mathrm{PO} 4$ P-lim & $1.57 \times 10^{-5}$ & $2.49 \times 10^{-1}$ & $1.23 \times 10^{-4}$ & $2.35 \times 10^{-1}$ & $2.49 \times 10^{-1}$ & $2.36 \times 10^{-1}$ \\
\hline Global warming & $\mathrm{kgCO}_{2} \mathrm{eq}$ & $1.37 \times 10^{-1}$ & $2.72 \times 10$ & $1.72 \times 10^{-1}$ & $2.57 \times 10$ & $2.73 \times 10$ & $2.59 \times 10$ \\
\hline $\begin{array}{l}\text { Non-renewable } \\
\text { energy }\end{array}$ & MJ primary & 2.21 & $2.69 \times 10^{2}$ & 2.77 & $2.55 \times 10^{2}$ & $2.71 \times 10^{2}$ & $2.58 \times 10^{2}$ \\
\hline Human toxicity & CTUh & $3.45 \times 10^{-11}$ & $2.58 \times 10^{-5}$ & $4.33 \times 10^{-11}$ & $2.93 \times 10^{-5}$ & $2.58 \times 10^{-5}$ & $2.93 \times 10^{-5}$ \\
\hline
\end{tabular}

The collection/trans-shipment stage is characterized by all activities related to ULO collection at the generation center, trans-shipment (absent or present, depending on the management scenario under anaysis) at the collection center, and where subsequent destinations of the re-refining industry are conducted. The last process stage refers to the basic oil production by ULO re-refining. It consists of an industrial process that enables the removal of the contaminants and constitutes the main emissions source (for air, water, and soil) of the ULO life cycle [45], referring to the environmental dimension of sustainability as a central issue caused by the crude production process.

\subsection{Social Assessment}

Social data are mostly qualitative, therefore, they were transformed using SAM into semi-quantitative and quantitative results by categorization and punctuation, respectively, as shown in Table 2. The results were thus presented to allow the use of the model for the categorization of the available information set. It is worth remembering that the results framings of the two scenarios (TTR and TsTR) were reflected when analyzing these results.

Table 2. ULO sub-categories and SAM scores of the social dimension.

\begin{tabular}{|c|c|c|c|c|c|c|}
\hline \multirow{3}{*}{$\begin{array}{l}\text { Workers' Stakeholder } \\
\text { Sub-Categories [16] }\end{array}$} & \multicolumn{6}{|c|}{ Stage } \\
\hline & \multicolumn{2}{|c|}{ Generation } & \multicolumn{2}{|c|}{ Collection/Trans-Shipment } & \multicolumn{2}{|c|}{ Re-Refining } \\
\hline & Categories & Score & Categories & Score & Categories & Score \\
\hline Working hours & B & 3 & B & 3 & B & 3 \\
\hline Fair salary & $\mathrm{B}$ & 3 & $\mathrm{~B}$ & 3 & $\mathrm{~B}$ & 3 \\
\hline $\begin{array}{l}\text { Freedom of association and } \\
\text { collective bargaining * }\end{array}$ & B & 3 & $\mathrm{C}$ & 2 & - & - \\
\hline Health and safety & $\mathrm{B}$ & 3 & B & 3 & $\mathrm{C}$ & 2 \\
\hline Child labor & $\mathrm{B}$ & 3 & B & 3 & B & 3 \\
\hline
\end{tabular}

* The re-refining stage results for this subcategory were not presented due to the unavailability of this information by workers and the interviewees responsible.

The data referred to the workers' stakeholders. It should be noted that the subcategories of equal opportunities/discrimination, forced labor, and social benefits, referenced by the UNEP/SETAC guide as parties of interest in this category, were disregarded [16]. In this dimension, each stage that constitutes the ULO management system is a legal entity or a social organization. Thus, a ULO management system can be constituted by two or three social organizations according to the scenario. The TsTR scenario was characterized by the exclusion of the organization related to the ULO collection and the activities developed by the latter are carried out by the re-refinery company. Table 3 shows 
the indicator performances of the established scenarios through the BR for evaluating the social dimension categories.

Table 3. Social performance indicators of workers' stakeholders in the scenarios.

\begin{tabular}{|c|c|c|c|c|c|c|}
\hline \multirow{3}{*}{$\begin{array}{l}\text { Workers' Stakeholder } \\
\text { Sub-Categories [16] }\end{array}$} & \multicolumn{3}{|c|}{ TsTR Scenario } & \multicolumn{3}{|c|}{ TTR Scenario } \\
\hline & \multicolumn{6}{|c|}{ BR Performance } \\
\hline & Satisfactory & Inadequate & Unsatisfactory & Satisfactory & Inadequate & Unsatisfactory \\
\hline Working hours & $\checkmark$ & & & $\checkmark$ & & \\
\hline Fair salary & $\checkmark$ & & & $\checkmark$ & & \\
\hline $\begin{array}{l}\text { Freedom of association } \\
\text { and collective bargaining }\end{array}$ & $\checkmark$ & & & & $\checkmark$ & \\
\hline Health and safety & & $\checkmark$ & & & $\checkmark$ & \\
\hline Child labor & $\checkmark$ & & & $\checkmark$ & & \\
\hline
\end{tabular}

\subsection{Economic Results}

The main costs involved in the ULO generation process were analyzed because the ULO generation centers have several activities (general mechanics, mechanic workshops and fuel supply, convenience store services, and gas stations) in addition to the ULO exchange. As a result, the fixed costs were allocated to the ULO exchange process, considering that they represented $10 \%$ of the generation site costs. Inflation was assumed to be zero $(0 \%)$. This possibility can be assumed when the presented data set refers to the average costs of the goods and services that constitute the process without significant changes in the period under analysis $[19,23,31]$. The presented results refer to the average costs of the goods and services constituting the ULO management system in the 2015/2016 period. Table 4 illustrates the economic results related to the costs in each stage according to the scenarios established for evaluation (TTR and TsTR).

Table 4. OLUC monetary results of the economic life cycle indicators.

\begin{tabular}{|c|c|c|c|c|c|c|c|}
\hline \multirow{2}{*}{ Categories } & \multicolumn{2}{|c|}{$\begin{array}{l}\text { TsTR Scenario Costs } \\
\text { (BRL/kg) }\end{array}$} & \multicolumn{3}{|c|}{ TTR Scenario Costs (BRL/kg) } & \multicolumn{2}{|c|}{ Total (BRL/kg) } \\
\hline & Generation & Re-Refining & Generation & Collection/Trans-Shipment & Re-Refining & TsTR & TTR \\
\hline Initial acquisition costs & 0.919 & 3.34 & 0.919 & 1.208 & 3.08 & 4.259 & 5.207 \\
\hline Transportation costs & 0.00 & 0.15 & 0.00 & 0.25 & 0 & 0.15 & 0.25 \\
\hline Installation costs & 0.337 & 2.55 & 0.337 & 1.683 & 1.85 & 2.887 & 3.87 \\
\hline $\begin{array}{c}\text { Operating and } \\
\text { maintenance costs }\end{array}$ & 0.615 & 2.363 & 0.615 & 1.411 & 1.97 & 2.978 & 3.997 \\
\hline Lost production cost & 0.00 & 0 & 0.00 & 0 & 0 & 0 & 0 \\
\hline $\begin{array}{l}\text { Net replacement } \\
\text { cost/income factor }\end{array}$ & -0.950 & -5.31 & -0.95 & -1.23 & -5.31 & -6.26 & -7.495 \\
\hline Stage Total & 0.921 & 3.094 & 0.921 & 3.317 & 1.593 & 4.015 & 5.831 \\
\hline
\end{tabular}

The TsTR scenario excluded the trans-shipment stage and, consequently, the costs of this stage were reflected in the re-refining stage because the re-refinery companies are responsible for the ULO collection and transportation. The opposite occurred in the TTR scenario wherein the costs were distinct in the three steps.

\subsection{Sustainability Assessment}

In the ULO life cycle sustainability assessment, three dimensions of data had to be aggregated in order to make the defined sustainability assessment comparable. The three dimensions were assumed to have the same weight as they were analyzed from a 
non-formal weighting perspective to support the sustainability perspective. The casual assessment referred by [46] played a vital role in the evaluation of the three sustainability pillars as it allows for scoping out possible future developments and alternative actions in the ULO life cycle. Table 5 presents the result dimensions, their conversions in contribution percentage, and their scores through the methodology suggested by $[39,43]$ with the purpose of obtaining the sustainability factors used in the evaluation of the sustainability life cycle by the sustainability index. This perspective was defined as an important way to analyze the trends of the data. It was used to choose the sustainability model that could be applied to make an accurate prediction of the life cycle $[47,48]$.

Table 5. Impact, contribution, and score category results of the three life cycle sustainability dimensions.

\begin{tabular}{|c|c|c|c|c|c|c|c|c|}
\hline \multirow{2}{*}{ Dimension } & \multirow{2}{*}{ Impact Categories } & \multirow{2}{*}{ Units } & \multicolumn{2}{|c|}{ Scenarios } & \multicolumn{2}{|c|}{ Contributions (\%) } & \multicolumn{2}{|c|}{ Scores * } \\
\hline & & & TTR & TsTR & TTR & TsTR & TTR & TsTR \\
\hline \multirow{8}{*}{ 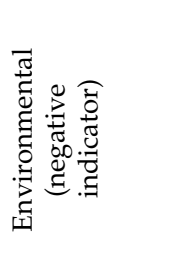 } & Carcinogens & $\mathrm{kg} \mathrm{C}_{2} \mathrm{H}_{3} \mathrm{Cl} \mathrm{eq}$ & 2.20 & 2.32 & 94.6 & 100 & 1 & 1 \\
\hline & Terrestrial ecotoxicity & kg TEG soil & $9.80 \times 10^{2}$ & $1.03 \times 10^{3}$ & 94.9 & 100 & 1 & 1 \\
\hline & Land occupation & $\mathrm{m}^{2}$ org.arable & 2.33 & 2.46 & 94.7 & 100 & 1 & 1 \\
\hline & Acidification & $\mathrm{kg} \mathrm{SO}_{2} \mathrm{eq}$ & $1.23 \times 10^{-1}$ & $2.00 \times 10^{-1}$ & 61.6 & 100 & 2 & 1 \\
\hline & Eutrophication & kg PO4 P-lim & $2.36 \times 10^{-1}$ & $2.49 \times 10^{-1}$ & 94.3 & 100 & 1 & 1 \\
\hline & Global warming & $\mathrm{kg} \mathrm{CO}_{2} \mathrm{eq}$ & $2.59 \times 10$ & $2.73 \times 10$ & 94.1 & 100 & 1 & 1 \\
\hline & Non-renewable energy & MJ primary & $2.58 \times 10^{2}$ & $2.71 \times 10^{2}$ & 95.0 & 100 & 1 & 1 \\
\hline & Human toxicity & CTUh & $2.93 \times 10^{-5}$ & $2.58 \times 10^{-5}$ & 100 & 87.9 & 1 & 1 \\
\hline \multirow{5}{*}{ 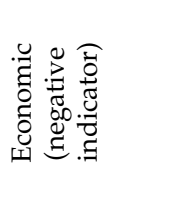 } & Initial acquisition costs & $\mathrm{BRL} / \mathrm{m}^{3}$ & 5.207 & 4.259 & 100 & 82.4 & 1 & 1 \\
\hline & Transportation costs & $\mathrm{BRL} / \mathrm{km}$ & 0.25 & 0.15 & 100 & 60 & 1 & 2 \\
\hline & Installation costs & BRL & 3.87 & 2.887 & 100 & 74.4 & 1 & 2 \\
\hline & $\begin{array}{l}\text { Operating and } \\
\text { maintenance costs }\end{array}$ & BRL & 0 & 0 & - & - & - & - \\
\hline & Lost production cost & BRL & 3.997 & 2.978 & 100 & 74.5 & 1 & 2 \\
\hline \multirow{5}{*}{ 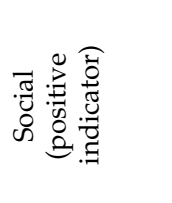 } & Working hours & hrs/day & 3 & 3 & 100 & 100 & 5 & 5 \\
\hline & Fair salary & BRL/month & 3 & 3 & 100 & 100 & 5 & 5 \\
\hline & $\begin{array}{l}\text { Freedom of association } \\
\text { and collective bargaining }\end{array}$ & $\%$ & 2 & 3 & 66.6 & 100 & 4 & 5 \\
\hline & Health and safety & $\%$ of accidents & 3 & 2 & 100 & 66.6 & 4 & 4 \\
\hline & Child labor & $\%<14$ years & 3 & 3 & 100 & 100 & 5 & 5 \\
\hline
\end{tabular}

* Scores: negative indicators $(0-20 \%=5 ; 21-40 \%=4 ; 41-60 \%=3 ; 61-80 \%=2 ;$ and $81-100 \%=1)$ and positive indicators $(0-20 \%=1$; $21-40 \%=2 ; 41-60 \%=3 ; 61-80 \%=4 ;$ and $81-100 \%=5)$.

This assessment considered, but did not segregate, environmental, social, and economic dimension. According to [49,50], the sustainability impact indices can be classified into three major categories. The environmental impacts in five of the eight categories (carcinogenic, terrestrial toxicity, land use, global warming, and use of fossil fuels) are fundamentally associated with the country's energy matrix and responsible for about $62.5 \%$ of the ULO life cycle impacts, while the remaining $37.5 \%$ of impacts derive from re-refining process emissions that mostly impact three categories (acidification, eutrophication, and human toxicity). In relation to the stages, the re-refining stage is the main stage directly responsible for the ULO life cycle impacts, contributing about $99 \%$. Transport does not significantly influence the impacts studied in this dimension [49], pointing to the need to analyze the different processes that constitute a system as a way to bring the perspective of which processes influence the system and to what extent in terms of their contribution to the results of the environment dimension.

The ULO management process cost for $1 \mathrm{~kg}$ basic oil production varied between BRL 4.014 and BRL 5.829. This variation was related to the implemented scenario type of the management system. The system with a TsTR scenario was economically better than the TTR scenario because its costs were about $31 \%$ lower than the TTR life cycle costs. A TsTR management system is characterized by not presenting the costs of collection/transshipment. This absence makes it economically better than the TTR scenario. The stages that make up the ULO life cycle have different economic contributions. The generation stage in the two scenarios is the one that contributed the least to the cycle costs $(22.9 \%$ in the TsTR and $15.8 \%$ in the TTR), followed by the collection/trans-shipment stage (56.9\%), which presented $77.1 \%$ in the TsTR scenario and $27.3 \%$ in the TTR scenario, caused by 
the presence or absence of the collection/trans-shipment center. ULO life cycle costs, which translate into generation, collection, and re-refining costs, have little variation in that they are regulated by the re-refining union companies that monitor both the basic oil market and the waste they use in their production process. This analysis defines which scenario is more eco-efficient, such as in the perspective of [30,51]; this refers to the method of delivering competitively priced goods that satisfy human needs while reducing the intensity of resource extraction and ecological impacts. The differences between the scenarios are mentioned by $[19,52]$ as impacting the LCC by, on the one hand, presenting high waste re-utilization and, on the other hand, having lower wastage rates, which promote sustainability issues defined by the management cost of the product.

The ULO management system presents a set of relevant social aspects related to the workers' stakeholders. The TTR management scenario is characterized by a higher employability percentage, employing a greater number of workers in relation to the TsTR scenario, caused by the presence of a collection/trans-shipment center. The increase in the number of workers and, consequently, the improvement in social conditions of social groups covered by the activity did not affect the social performance scenario. On the contrary, the study showed that the presence of the collection/trans-shipment center increased occupational workers' risks, reducing the system performance in an equivalent scenario. The TsTR scenario presented a better social performance compared to the four BR (working hours, freedom of association and collective bargaining, child labor, and fair salary) of workers' stakeholders. This is why it was socially better than the TTR scenario system that presents two (freedom of association and collective bargaining, worker health and safety) of the five subcategories with inadequate performance. This was a consequence of work accident report occurrences and the absence of freedom of association and collective bargaining.

The scores obtained in each indicator were used to calculate the respective sustainability factors (environmental, economic, and social) that are urgently required, as indicated by $[46,47]$, to evaluate the sustainability of a life cycle. These sustainability factors vary in magnitude from 0 to 1 and make it possible to compare the dimensions in the sustainability perspective of the evaluated scenarios. The sustainability factors of each scenario dimensions are presented in Table 6.

Table 6. Score and sustainability factor congregation.

\begin{tabular}{cccccc}
\hline \multirow{2}{*}{ Dimension } & \multicolumn{2}{c}{ Scenarios Scores } & \multicolumn{3}{c}{ Sustainability Factors } \\
\cline { 2 - 6 } & TTR & TsTR & SF & TTR & TsTR \\
\hline Environmental & 9 & 8 & SFenvironmental & 1 & 0.88 \\
\hline Economic & 4 & 7 & SFeconomic & 0.57 & 1 \\
\hline Social & 23 & 24 & SFsocial & 0.95 & 1 \\
\hline & Total score for each scenario & & 2.52 & 2.88 \\
\hline
\end{tabular}

The sustainability factors in relation to the TTR and TsTR scenarios are presented in Figure 2. These show how environmental, economic, and social sustainability factors influenced the sustainability index in the two OLUC management scenarios. The difference in the scenarios' performances is given by the percentage variation of the sustainability index, which in the case of TTR and TsTR was $12.5 \%$, a considerable difference. Due to the need to define the best scenario for sustainability, partial analyses of each dimension were conducted, aiming to find the dimensions that contribute the most to influencing the sustainability index in one scenario or another. A conduct sustainability assessment is clearly needed for a systematic analysis of these dimensions to fill the gap for betterinformed decision makers and to make these three dimensions more integrated with some more well-established life cycle methodologies by aligning them with the phases defined in the base standard (ISO 14040) and other sowed by [53]. 


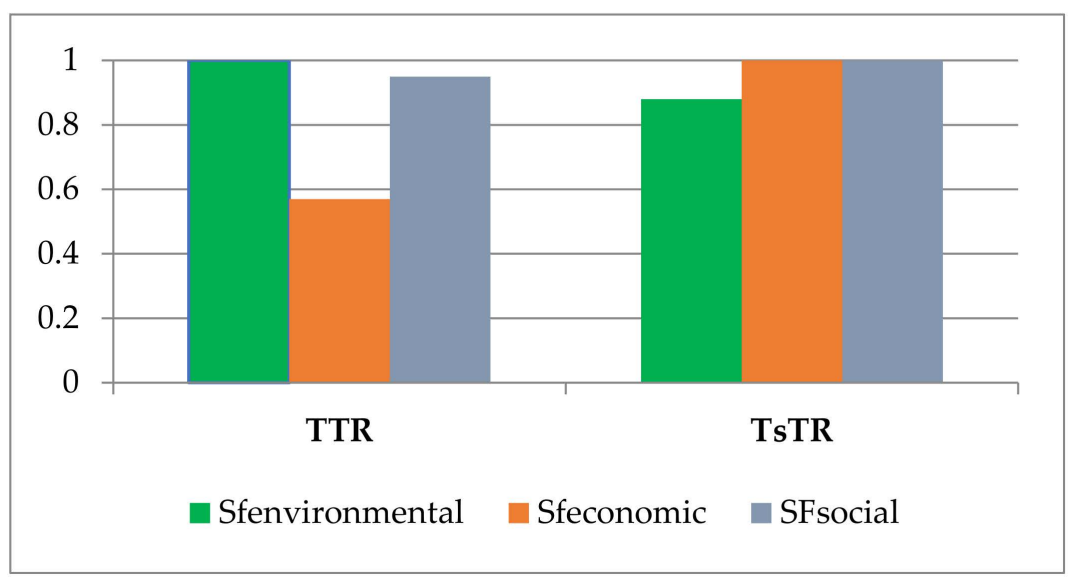

Figure 2. TsTR and TTR sustainability factor performances.

The system with the TTR scenario was characterized by a better environmental performance $(\mathrm{SF}=1)$, with a percentage difference in relation to the index of about $12 \%$ when compared to the TsTR scenario ( $\mathrm{SF}=0.88$ ). This difference is justified by the fact that, in the TTR scenario, the OLUC that arrived at the re-refinery had undergone a pre-treatment in the trans-shipment center by decanting the removal of part of the water that composes the collected mixture in the generation center. Among the eight categories of environmental impacts, the TsTR scenario presents the highest contributions in seven categories (carcinogens, terrestrial ecotoxicity, land use, eutrophication, global warming, fossil fuel use, and acidification), which makes it environmentally poor compared to the TTR scenario.

The best environmental performance recorded by the TTR scenario was a consequence of the absence of the effluent treatment process launched by the collection/trans-shipment centers in its cycle. Collection/trans-shipment centers discharge their effluents into water (river) bodies while observing the established legal limits. These effluents, although highly diluted, carry quantities of substances that would increase the magnitude of the emissions in the re-refining process. It is worth noting that there are environmental requirements regarding the discharge standards for liquid effluents established by the OEMA (state environmental agency) that must be met by the collection/transshipment centers, since trans-shipment centers because CONAMA resolution nr. 430/11 [54], prohibits its launching in sewage networks, even when diluted.

Regarding the economic aspect, the TsTR scenario presents presented a better economic performance $(\mathrm{SF}=1)$ than the TTR scenario $(\mathrm{SF}=0.57)$. The justification for this difference of about $40 \%$ is the presence of the collection/transshipment trans-shipment center in the TTR scenario, which means that there is was one more location (besides the generation and re-refinery site) with economic flows in the OLUC management chain. The collection/overflow center presents a set of costs related to all items analyzed items (initial acquisition costs, transportation costs, installation costs, net replacement cost, operating and maintenance costs) and this makes the system financially higher than the TsTR scenario, scenario due to the fact that it does not present this stage and consequently with and, consequently, bears zero costs related to the collection/transshipment trans-shipment stage.

An aspect to be considered consider in the economic dimension is the cost discriminated discrimination analysis related to each management system stage where wherein it is observed that that, although the TTR scenario is was economically more expensive than the TsTR, their stages (constituted by companies associated or not) show showed another trend of expenditure relative to the system components. While in the TsTR scenario, the total life cycle costs are were lower than those in the TTR scenario, the organizations that make up the systems (TTR: generation, collection/transshipment trans-shipment, and re-refining company; TsTR: generation and re-refining company) show that the TsTR re-refining company's company costs are were greater than the TTR re-refining company's company costs. This is justified, therefore, justified because part of the financial activity developed in the 
TTR re-refining company is was performed by the collection/transshipment trans-shipment company. If it is assumed that these are unrelated companies, where wherein each one assumes the activity costs, the re-refining process will would be more expensive in the TsTR scenario than in the TTR.

The discriminated costs for the companies of each scenario companies showed a better tendency for in the TTR scenario, where wherein the re-refining company has had about $47 \%$ of its production costs reduced, giving it good financial consistency when compared to the TsTR retreading company. However, a cycle analysis (total cost) shows showed a different trend, where wherein the TsTR scenario is economically more viable than the TTR scenario. The social dimension showed satisfactory performance for the two scenarios ( $\mathrm{SF}=1$ and $\mathrm{SF}=0.95$ for TsTR and TTR, respectively). The TsTR scenario presents presented a relatively better performance than the TTR. One of the social organizations in the TsTR scenario (the re-refining company) presents presented a subcategory with inadequate performance (workers' health and safety). The same occurs occurred in the TTR scenario, where wherein two of the organizations that constitute it (collection/transshipment transshipment and re-refinery Company) present showed inadequate performance in two subcategories (freedom of association and collective bargaining, and health and safety of workers). Subcategories, where Subcategories wherein organizations do not meet the basic requirements, requirements influence the overall organization performance. The TTR system has had two organizations that do did not meet the basic requirements for certain subcategories, which makes caused it to perform poorly than compared to the TsTR system.

This assessment is was the result of a pragmatic LCSA which that is especially dependent on the three separate methods, which methods that have different levels of data available and maturity, as proposed by [53], taking into account the developed tool, methodological issues about the impact assessment, the interpretation of results, and the findings of the outcomes. Therefore, based on this assumption, the sustainability index was calculated by each sum of the arithmetic factors' means. Its interpretation is was based on the sustainability principle, defined as a system that can remain balanced or in balance according to different sustainability dimensions analyzed ("triple bottom line" model, for the case under study) analyzed). This life cycle sustainability is influenced by the characteristics and the relationships existing between the dimensions. The TTR scenario showed good environmental performance, high management costs, and good social performance. Thus, the collection/transshipment trans-shipment center presence has increased management costs and reduced the contaminants load in ULO, but their organizations have had problems with working conditions. In a different way, the absence of a collection/transshipment trans-shipment center absence in the TsTR scenario made this system's environmental performance poor, but it showed low production costs and satisfactory social performance. Figure 3 shows the degree of sustainability of the scenarios proposed in the ULO life cycle sustainability assessment.

The ULO life cycle sustainability index is was different for the TsTR and TTR scenarios. The TsTR scenario was characterized by a better sustainability index, SI = $2.88(96 \%)$, compared to the TTR scenario with scenario, SI $=2.52(84 \%)$. The TTR's inadequate social performance can be improved by reaching the basic requirements concerning the workers' social conditions in the organizations that make up this cycle. In this case, this would be by creating and making available the conditions for freedom of association and collective bargaining in a social organization corresponding to the collection/transshipment transshipment stage. The improvement of in social conditions, translated by the decrease in the number of occupational hazards related to workers' health and safety, in the re-refinement phase, shows phase showed the improvement of in social performance in this scenario. The costs related to the TTR scenario can be reduced through social organizations' aggregation translated by the generation and re-refining stage. This situation enables the elimination of costs related to the ULO acquisition at the refinery gate, gate as well as the reduction of in total acquisition and installation costs. The approach used to design and develop a sustainability assessment is referred by $[14,18,51]$ as a way to develop product-service 
solutions and can be also be considered a holistic analysis to support system thinking in sustainability decision making.

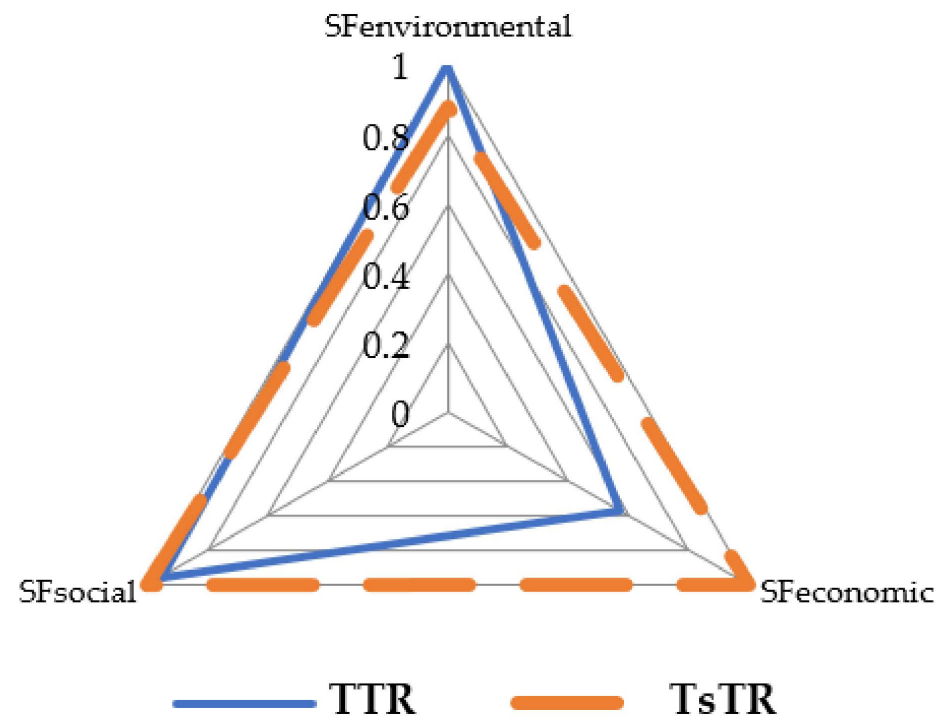

Figure 3. ULO life cycle sustainability scenarios.

\section{Conclusions}

The ASCV methodology allows, through the weighted and combined evaluation of equivalent weights assigned to the three dimensions, the ASCV methodology helps to make a life cycle assessment comparative of to the production process through, in this case, the evaluation of the alternative systems of ULO management by the Index of Sustainability of each scenario. This index allows helps to analyze the contributions of each of the 18 categories and subcategories (8 eight environmental, 5 five economic, and 5 five social) in the respective sustainability dimensions and consequently and, consequently, to carry out their integrated evaluation, aiming to define the best sustainability scenario.

The evaluation of the scenarios indicates that the ULO TsTR management system, consisting of a ULO generation company and a re-refining generation company, tends to generate a higher sustainable index than the TTR system. The presence of a transshipment trans-shipment center in the TTR scenario shows benefits in this cycle cycle's environmental approach, but however, it is not economically feasible and doesn't have a does not show good social performance. In turn, a system with the TsTR scenario has more environmental impacts than TTR. However, it is economically viable and shows good social performance. The TTR scenario system is environmentally less impacting impactful than the TsTR scenario in relation to the categories analyzed in the environmental dimension. This cycle cycle's environmental assessment indicates that the TTR scenario only contributes to greater impacts in the human toxicity category, category while the TsTR scenario has a larger contribution in seven of the eight impact categories analyzed. The presence of the collection/transshipment trans-shipment center in the TTR scenario, scenario conditions the lower contribution of this system to the environmental impacts in relation to the defined impact categories.

We found that the application of LCSA methodology in ULO management is was very low. There is a need for further research in order to improve and evaluate the subjective analysis that characterizes this methodology that is mainly caused by various indicators of a social dimension that are not quantified and the an economic dimension that is strongly influenced by inflation. 
Author Contributions: M.Z.A.T.-lead author, research design and design, method, data collection, and analysis; C.F.d.A.—data analysis by software; C.M.L.U.-review and editing; L.F.d.A.C.-review and supervision. All authors have read and agreed to the published version of the manuscript.

Funding: This research received no external funding.

Institutional Review Board Statement: Not applicable.

Informed Consent Statement: Not applicable.

Data Availability Statement: Primary data that support this research can be found in at the following link: http:/ /lalca.acv.ibict.br/lalca/article/view/4236 (accessed on 2 November 2020).

Acknowledgments: The authors are grateful to the valuable contributions of the Center of Life Cycle Sustainability Assessment of the Federal University of Technology (GYRO/UTFPR).

Conflicts of Interest: The authors declare no conflict of interest.

\section{References}

1. Mang, T.; Gosalia, A. Lubricant and their market. In Lubricants and Lubrication, 3rd ed.; Mang, T., Dresel, W., Eds.; Wilwy-VCH: Weinheim, Germany, 2017.

2. Tsambe, M.Z.A.; Almeida, C.F.; Ugaya, C.M.L.; Cybis, L.F.A. Environmental Assessment of Used Lubricant Oil in Southern Brazilian Region. J. Environ. Account. Manag. 2019, 7, 381-394. [CrossRef]

3. Sohn, H. Guia Básico: Gerenciamento de óleos Lubrificantes Usados ou Contaminados; GMP/SENAI: Brasília, Brazil, 2011.

4. SINDIRREFINO. Logística Reversa de óleos Lubrificantes e Rerrefino. Brasília. 2014. Available online: https://www.sindirrefino. org.br/rerrefino/logistica-reversa-oluc (accessed on 5 November 2019).

5. ANP-National Agency of Petroleum, Natural Gas and Biofuels. Bolentim de Lubrificantes. 2017. Available online: https: //www.gov.br/anp/pt-br/centrais-de-conteudo/publicacoes/boletins-anp/boletim-de-lubrificantes (accessed on 21 June 2018).

6. SINDIRREFINO. Relatórios do Sindicato. 2017. Available online: https://www.sindirrefino.org.br/ (accessed on 15 November 2019).

7. Tsambe, M.Z.A.; Almeida, C.F.; Ugaya, C.M.L.; Cybis, L.F.A. Avaliação do Sistema de Gerenciamento de Óleos Lubrificantes Usados ou Contaminados no Brasil. Tecno Lógica 2017, 21, 57-79. [CrossRef]

8. EC-European Commission. Integrated Pollution Prevention and Control. In Reference Document on Best Available Techniques of the Waste Treatments Industries; EC-European Commission: Brussels, Belgium, 2006.

9. CONAMA —Conselho Nacional de Meio Ambiente. Resolução 362/2005: Regulamentação da Coleta, Transporte, Armazenamento e Destinação Adequada dos Óleos Lubrificantes Usados e Contaminados. Brasília. 2005. Available online: http: / / conama.mma.gov.br/?option=com_sisconama\&task=arquivo.download\&id=457 (accessed on 2 June 2018).

10. Leskinen, P. Multi criteria analysis of social and environmental impacts. Environmental Assessment \& Integrated Assessment Complex Systems Biosystems. In Proceedings of the Water \& Land Management Conference, Montpellier, France, 13 December 2011.

11. Kloepffer, W. Life cycle sustainability assessment of products. Int. J. Life Cycle Assess. 2008, 13, 89. [CrossRef]

12. Guinée, J.B.; Heijungs, R.; Huppes, G.; Zamagni, A.; Masoni, P.; Buonamici, R.; Ekvall, T.; Rydberg, T. Life cycle assessment: Past, present, and future. Environ. Sci. Technol. 2011, 45, 90-96. [CrossRef]

13. Gundes, S. The Use of Life Cycle Techniques in the Assessment of Sustainability. Procedia Soc. Behav. Sci. 2016, 216, 916-922. [CrossRef]

14. Vinyes, E.; Oliver-Solà, J.; Ugaya, C.M.L.; Rieradevall, J.; Gasol, C.M. Application of LCSA to used cooking oil waste management. Int. J. Life Cycle Assess. 2013, 2, 445-455. [CrossRef]

15. Ciroth, A.; Franze, J. Conducting a Social LCA. GreenDeltaTC Workshop-Social Aspects of Products Over the Whole Life Cycle. In Tools E Consulting for Sustainability; GreenDelta TC: Berlin, Germany, 2011.

16. UNEP-United Nation Environmental Protection. Guidelines for Social Life Cycle Assessment of Products; Life Cycle Initiative/UNEP/SETAC; CIRAIG-Interuniversity Research Center for Life Cycle of Products, Process and Services: Brussels, Belgium, 2009; ISBN 978-92-807-3021-0.

17. Fiksel, J.; McDaniel, J.; Mendenhall, C. Measuring progress towards sustainability principles, process, and best practices. In Proceedings of the 1999 Eighth International Conference of Greening of Industry Network, Chapel Hill, NC, USA, 14-17 November 1999.

18. Atilgan, B.; Azapagic, A. An integrated life cycle sustainability assessment of electricity generation in Turkey. Energy Policy 2016, 93, 168-186. [CrossRef]

19. Wong, N.H.; Tay, S.F.; Wong, R.; Ong, C.L.; Sia, A. Life cycle cost analysis of rooftop gardens in Singapore. Build. Environ. 2003, 38, 499-509. [CrossRef]

20. Nakaniwa, C.; Graedel, T.E. Life cycle and matrix analyses for re-refined Oil in Japan. Int. J. Life Cycle Assess. 2002, 7, 95-102. [CrossRef]

21. Pires, A.; Martinho, G. Life cycle assessment of a waste lubricant oil management system. Int. J. Life Cycle Assess. 2013, 18, 102-112. [CrossRef] 
22. Unnasch, S.; Waterland, L. Critical Review of Used Oil Life Cycle Assessment Study; California Department of Resources Recycling and Recovery: Sacramento, CA, USA, 2013.

23. Finkbeiner, M.; Schau, E.M.; Lehmann, A.; Traverso, M. Towards Life Cycle Sustainability Assessment. Sustainability 2010, 2, 3309-3322. [CrossRef]

24. Zamagni, A. Life cycle sustainability assessment. Int. J. Life Cycle Assess. 2012, 17, 373-376. [CrossRef]

25. Ciroth, A. Cost data quality considerations for eco-efficiency measures. Ecol. Econ. 2009, 68, 1583-1590. [CrossRef]

26. Tsambe, M.Z.A.; Almeida, C.F.; Ugaya, C.M.L.; Cybis, L.F.A. Inventário de Ciclo de Vida de Óleos Lubrificantes Usados ou Contaminados na Região Sul do Brasil. LALCA R. Latino Amer. Aval. Ciclo Vida 2019, 2, 9-33. [CrossRef]

27. ISO-International Organization for Standardization. ISO 14040:2006. Environmental Management-Life Cycle Assessment: Principles and Framework, 2006. Available online: https:/ / www.iso.org/standard/37456.html (accessed on 21 May 2019).

28. ISO-International Organization for Standardization. ISO 14044:2006. Environmental Management-Life Cycle Assessment: Requirements and Guidelines, 2006. Available online: https:/ /www.iso.org/standards.html (accessed on 28 May 2019).

29. Rac, A.; Vencl, A. Ecological and technical aspects of the waste oils influence on environment. In Proceedings of the 3rd International Conference on DIPRE, Bucharest, Romania, 31 May-1 June 2012; Volume 1, pp. 5-11.

30. UNEP-United Nation Environmental Protection. Environmental Life Cycle Cost: A Code of Practice; Swarr, T.E., Hunkeler, D., Klöpffer, W., Pesonen, H.-L., Ciroth, A., Brent, A.C., Pagan, R., Eds.; SETAC Press: Brussels, Belgium, 2011.

31. Santos, L.J.C. Avaliação do Ciclo de Vida e Custeio do Ciclo de Vida de Evaporadores Para Usinas de Açúcar (Doutorado em Engenharia Metalúrgica e de Materiais). Ph.D. Thesis, Universidade de São Paulo, São Paulo, Brazil, 2017.

32. Nilsson, J.; Bertling, L. Maintenance Management of Wind Power Systems Using Condition Monitoring Systems Mdash: Life Cycle Cost Analysis for Two Case Studies. IEEE Trans. Energy Convers. 2007, 22, 223-229. [CrossRef]

33. Schau, E.M.; Traverso, M.; Finkbeiner, M. Life Cycle Costing in Sustainability Assessment-A Case Study of Remanufactured Alternators. Sustainability 2011, 3, 2268-2288. [CrossRef]

34. ISO-International Organization for Standardization. ISO 15663:2001. Petroleum and Natural Gas Industries—Life Cycle Costing, 2001. Available online: https:/ / www.iso.org/standard/28626.html (accessed on 4 June 2020).

35. Macombe, C.; Leskinen, P.; Feschet, P.; Antikainen, R. Social life cycle assessment of biodiesel production at three levels: A literature review and development needs. J. Clean. Prod. 2013, 52, 205-216. [CrossRef]

36. Wu, R.; Yang, D.; Chen, J. Social Life Cycle Assessment Revisited. Sustainability 2014, 6, 4200-4226. [CrossRef]

37. Parent, J.; Cucuzzella, C.; Revéret, J. Impact assessment in SLCA: Sorting the sLCIA methods according to their outcomes. Int. J. Life Cycle Assess. 2010, 15, 164-171. [CrossRef]

38. Ramirez, P.K.S.; Ugaya, C.M.L. Avaliação do perfil social do sabonete em barras Ekos cacao (maracatu) da natura utilizando um método de avaliação de subcategorias (SAM), in Sustainability Metrics from Cradle to Grave. In Proceedings of the 5th International Conference on Life Cycle Assessment CILCA, Mendoza, Argentina, 9-12 July 2013; pp. 650-657.

39. Ramirez, P.K.S.; Petti, L.; Haberland, N.T.; Ugaya, C.M.L. Subcategory assessment method for social life cycle assessment. Part 1: Methodological framework. Int. J. Life Cycle Assess. 2014, 19, 1515-1523. [CrossRef]

40. Hofstetter, P.; Braunschweig, A.; Mettier, T.; Müller-Wenk, R.; Tietje, O. The Mixing Triangle: Correlation and Graphical Decision Support for LCA-based Comparisons. J. Ind. Ecol. 1999, 3, 97-115. [CrossRef]

41. Singh, R.K.; Murty, H.R.; Gupta, S.K.; Dikshit, A.K. An overview of sustainability assessment methodologies. Ecol. Indic. 2012, 15, 281-299. [CrossRef]

42. Moslehi, S.; Arababadi, R. Sustainability Assessment of Complex Energy Systems Using Life Cycle Approach-Case Study: Arizona State University Tempe Campus. Procedia Eng. ICSDEC 2016 Integr. Data Sci. Constr. Sustain. 2016, 145, $1096-1103$. [CrossRef]

43. Ortiz, I.M. Life Cycle Assessment as a Tool for Green Chemistry: Application to Different Advanced Oxidation Processes for Wastewater Treatment. Ph.D. Thesis, Universitat Autònoma de Barcelona, Barcelona, Spain, 2006.

44. Zhou, Z.; Jiang, H.; Qin, L. Life cycle sustainability assessment of fuels. Fuel 2007, 86, 256-263. [CrossRef]

45. Sitepu, M.H.; Matondang, A.R.; Sembiring, M.T. Sustainability Assessment in Crude Palm Oil Production: A Review. IOP Conf. Ser. Mater. Sci. Eng. 2020, 725, 012074. [CrossRef]

46. Fauzi, R.T.; Lavoie, P.; Sorelli, L.; Heidari, M.D.; Amor, B. Exploring the Current Challenges and Opportunities of Life Cycle Sustainability Assessment. Sustainability 2019, 11, 636. [CrossRef]

47. Tayib, S.A.M.; Nor, S.R.M.; Norrulashikin, S.M. Forecasting the Crude Palm Oil Production in Malaysia using SARIMA model. IOP Conf. Ser. Publ. J. Phys. 2021, 1988, 012106. [CrossRef]

48. Onat, N.C.; Kucukvar, M.; Halog, A.; Cloutier, S. Systems Thinking for Life Cycle Sustainability Assessment: A Review of Recent Developments, Applications, and Future Perspective. Sustainability 2017, 9, 706. [CrossRef]

49. De Almeida, C.F.; Maciel, V.G.; Tsambe, M.Z.A.; Cybis, L.F.A. Environmental Assessment of Bi-fuel Power Plant in Isolated Power System in the Brazilian Amazon Region. J. Clean. Prod. 2017, 154, 41-50. [CrossRef]

50. Ribeiro, I.; Matos, F.; Jacinto, C.; Salman, H.; Cardeal, G.; Carvalho, H.; Godina, R.; Peças, P. Framework for Life Cycle Sustainability Assessment of Aditive Manufacturing. Sustainability 2020, 12, 929. [CrossRef]

51. Mendoza, J.M.; D’Aponte, F.; Gualtieri, D.; Azapagic, A. Disposable Baby Diapers: Life Cycle Cost, Eco-efficiency and Circular Economy. J. Clean. Prod. 2019, 211, 455-467. [CrossRef] 
52. Kianian, B. Comparing Acquisition and Operation Life Cycle Cost of Power Metallurgy and Conventional Wrought Steel Gear Manufacturing Techniques. Procedia CIRP 2019, 81, 1101-1106. [CrossRef]

53. Valdívia, S.; Backes, J.G.; Traverso, M.; Sonneman, G.; Cucurachi, S.; Guinée, J.B.; Schaubroeck, T.; Finkbeiner, M.; LeroyParmentier, N.; Ugaya, C.; et al. Principles to Application of Life Cycle Sustainability Assessment. Int. J. Life Cycle Assess. 2021, 26, 1900-1905. [CrossRef]

54. BRASIL. Resolução CONAMA Nr. 430/2011: Regulamentação Sobre Padrões de Lançamento de Efluentes; Conselho Nacional de Meio Ambiente. Available online: https:/ / www.legisweb.com.br/legislacao/ ?id=114770 (accessed on 19 September 2020). 